\title{
||||||||||||||||||||||||||||||||||||||||||||||||||||||||||||||||||||.
}

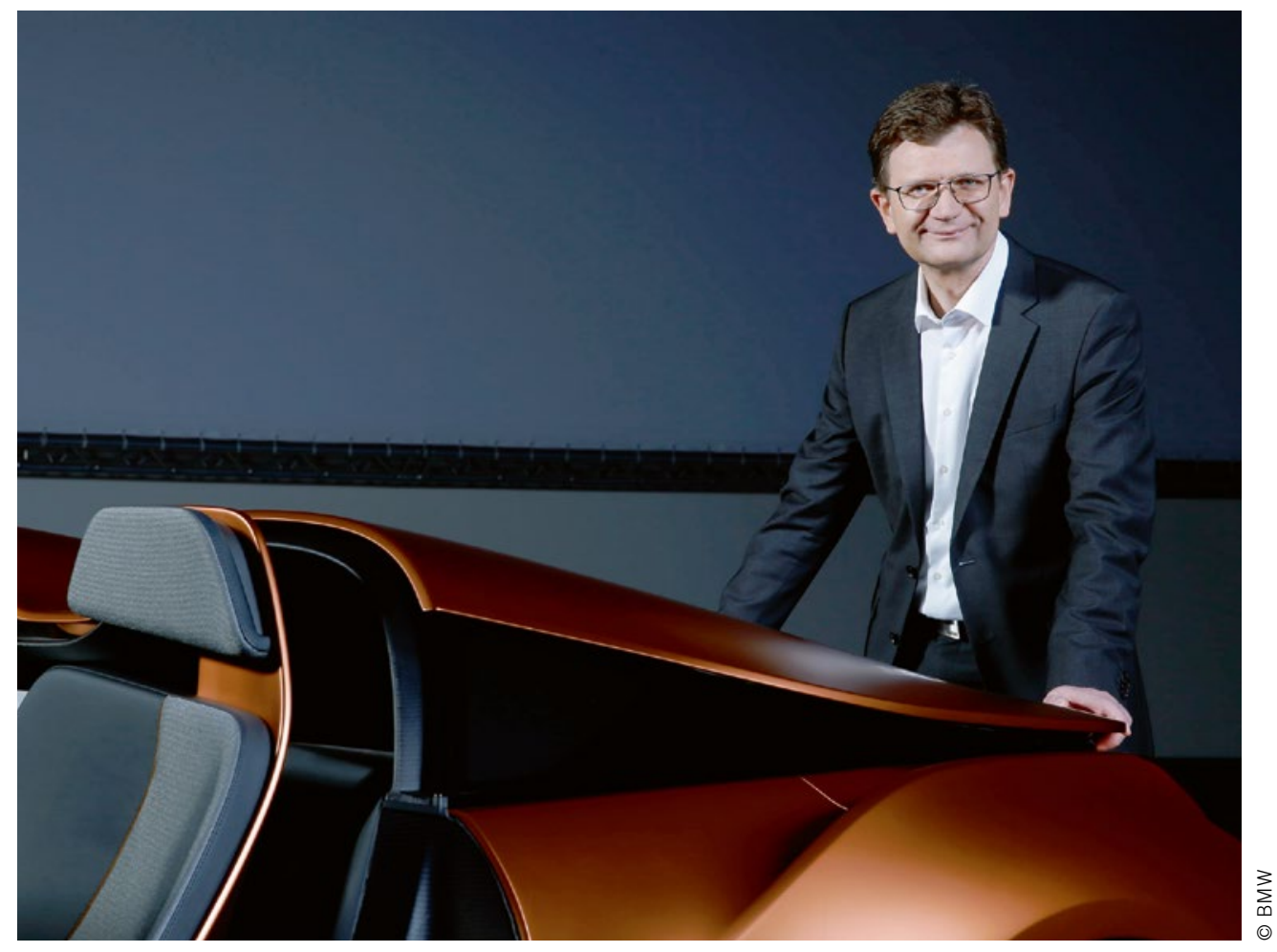

Dipl.-Ing. Klaus Fröhlich Mitglied des Vorstands der BMW AG, Entwicklung, ATZ-Beirat

\section{Vollautonom, hochvernetzt und emissionsfrei}

„Das Automobil wird sich in der nächsten Dekade stärker verändern als in den letzten fünfzig Jahren“, dies schrieb ich in meinem letzten Gastkommentar für die ATZ. Zwei Jahre später sehen wir, dass die Veränderungsgeschwindigkeit deutlich zugenommen hat. Gerade im Bereich des autonomen und hochautonomen Fahrens sind Entwicklungshübe notwendig und auch möglich, die wir vor wenigen Jahren noch nicht realisieren konnten.

Ich halte das autonome Fahren - im Gegensatz zu manchen „Marketing-Genies“ - für eine riesige Herausforderung. Es geht um nichts mehr oder weniger, als die menschliche Sinneswahrnehmung und die Denk- und Entscheidungsleistung des Gehirns durch ein intelligentes System zu ersetzen.

Für das autonome Fahren gibt es zwei Treiber: Der eine ist das Kundenbedürfnis, nicht immer selbst fahren zu wollen. Der zweite Treiber sind neue Businessmodelle. Für uns bei der BMW Group gilt dabei: Der Autofahrer entscheidet ganz nach der Situation. Entweder selbst fahren - in einem passgenau auf die eigenen Bedürfnisse ausgerichteten Fahrzeug, in dem sich alles um den „Ultimate Driver“ dreht: Wir nennen das „BoostModus“. Oder demnächst auch: personalisiertes automatisiertes Fahren mit all seinen Vorzügen von Entspannung bis Unterhaltung, der „Ease-Modus“.

Als einzelner Fahrzeughersteller allein werden wir diese Herausforderung aber nicht meistern können. Die Zukunft der
Automobilbranche hängt von den Rahmenbedingungen ab, aber vor allem auch von unserem Kooperationswillen. Wir haben die Felder, in denen wir uns mit Partnerschaften positionieren müssen, klar definiert. Mit dem gemeinsamen Kauf von Here durch uns und weitere OEMs haben wir dafür gesorgt, dass digitales Kartenmaterial weiterhin für alle im Markt zur Verfügung steht. Mit diesem Kartendienst haben wir Zugriff auf die hochauflösende Karte, neben der Sensorik im Auto die zweite wesentliche Grundvoraussetzung für autonomes Fahren. Jetzt arbeiten wir mit unseren Partnern Intel, Mobileye oder Delphi und Continental an der Industrialisierung der Sensortechnik und der Informationsverarbeitung im Auto. Was wir aus eigener Kraft bereits heute sehr gut können ist schließlich die Motion Control, die Auslegung und Steuerung des Fahrzeugs über Antrieb, Fahrwerk, Bremsen, aber auch die gesamte Systemintegration.

Wir bei BMW haben uns mit unserem Projekt iNext bis 2021 den Durchbruch zum vollautonomen Fahren vorgenommen. Natürlich wird der iNext auch emissionsfrei fahren. Das allein ist dann aber für uns nicht mehr innovativ. Mit der Befähigung zum vollautonomen Fahren, einer umfassenden Vernetzung und einem Interieur der Zukunft wird dieses Project i 2.0 ein Inkubator für die Innovationskraft der Marke sein. 